\title{
Representações de Grupos Nacionais entre Jovens Segundo o Grupo Étnico ${ }^{1}$
}

\author{
Angel Beldarrain-Durandegui ${ }^{2}$ \\ Loughborough University \\ Edson A. de Souza Filho \\ Universidade Federal do Rio de Janeiro
}

\begin{abstract}
RESUMO - O objetivo desta pesquisa foi descrever representações sociais (R.S.) sobre nações, segundo grupo étnico-racial autodefinido. Adotamos o referencial teórico das R.S. de Moscovici, articulado às teorias sobre relações intergrupais. Estudantes secundaristas de escolas públicas do Rio de Janeiro, autodefinidos como negro $(n=31)$, moreno $(n=88)$ e branco $(n=100)$, responderam um questionário sobre o Brasil, os EUA e os países árabes/muçulmanos. Sobre o Brasil, o "branco" enfatizou Estado/nação e interações interpessoais; o "negro", indivíduo e grupos particulares e, o "moreno", indivíduo face às normas sociais. O "moreno" mostrou dificuldade de manutenção de fronteiras intergrupais e menor distinção social. O "branco" descreveu os EUA como país que realça o indivíduo e considerou o Brasil mais satisfatório em termos interpessoais, segundo o modelo de "homem cordial" de Buarque de Holanda. A dificuldade de representar o Brasil em termos culturais, indica o menor reconhecimento das culturas negra e índia na construção social da sociedade brasileira.
\end{abstract}

Palavras-chave: representações sociais; grupos nacionais; relações intergrupais.

\section{Representations of National Groups among Youngsters According to Ethnic Group}

\begin{abstract}
This research aimed at describing social representations (S.R.) about nations, according to self-defined ethnicracial groups. We adopted Moscovici's theoretical referencial of S.R., in conjunction with intergroup relation theories. Secondary school students from public schools of Rio de Janeiro, self-defined as Black $(n=31)$, Dark-skinned $(n=88)$ and White $(n=$ 100), answered a questionnaire about Brazil, USA and Arab/Muslim countries. On Brazil, White people emphasized State/Nation and interpersonal interactions; Black people, the individual and particular groups; and Dark-skinned people, individual facing social norms. Dark-skinned people showed difficulty of keeping intergroup boundaries and low social distinction. White people described the USA as a country that enhances the individual and considered Brazil more satisfactory in interpersonal terms, according to the "cordial man's" model of Buarque de Holanda. The difficulty to represent Brazil in terms of culture indicates the lower recognition of Black and Native-American cultures in the social construction of the Brazilian society.
\end{abstract}

Key words: social representations; national groups; intergroup relations.

O objetivo deste trabalho foi analisar representações do Brasil, dos EUA e dos países árabes/muçulmanos entre jovens da cidade do Rio de Janeiro, autodefinidos étnica e racialmente. Como existem ainda poucos trabalhos a respeito da diversidade étnica em termos psicossociais no Brasil, consideramos pertinente realizar uma investigação exploratória tomando esta diversidade intercultural como hipótese de partida.

O nosso principal referencial teórico foi o das representações sociais (R.S.) (Moscovici, 1961/1976), no qual se defende a importância de fatores históricos e culturais na elaboração de idéias, crenças, opiniões e discursos por parte dos grupos. Moscovici (1961/1976) definiu as R.S.

1 Os autores agradecem a colaboração das escolas da rede pública da cidade do Rio de Janeiro, o apoio da CAPES pela concessão da bolsa de Mestrado recebida pelo primeiro autor (atualmente, doutorando no Department of Social Sciences - Loughborough University) e ao Programa de Pós-graduação em Psicologia da UFRJ.

2 Endereço: Loughborough University, Social Sciences Department, Brockington Building, Loughborough, Leicestershire, LE11 3TU, UK. E-mail: a.beldarrain-durandegui@lboro.ac.uk como formas de pensamento/ação partilhados por indivíduos e grupos nas sociedades. As R.S. permitem aos indivíduos apreenderem a realidade social e o mundo que os rodeia, dando-lhes um sentido e uma explicação estáveis. Ademais, as R.S. facilitam a comunicação social entre indivíduos e membros de um grupo, equipando-os de um código e sistema classificatório comuns para tratar as informações sobre outros sujeitos e objetos, estranhos ou pertencentes a outros ambientes socioculturais.

Segundo o mesmo autor, as R.S. são compostas por aspectos tanto icônicos quanto conceituais e são produzidas através de dois processos globais interligados: a objetivação e a ancoragem. A objetivação se realiza a partir de várias fases: inicialmente acontece uma seleção e descontextualização, na qual os assuntos são relidos com base em certos critérios culturais e normativos e acabam sendo selecionadas aquelas informações que concordam com o sistema de valores que predomina no ambiente dos sujeitos. Posteriormente, a formação do "núcleo ou esquema figurativo" completa a tarefa de relacionar o assunto com uma imagem ou figura palpável. Finalmente, através da naturalização, o que até 
então era uma noção estranha/ambígua/abstrata, torna-se evidência ao tomar corpo num objeto com o qual a idéia é associada, adquirindo uma forma determinada e reconhecível. Para Moscovici (2000), vivemos em sociedades heterogêneas onde diversos grupos constroem consensos entre os seus membros, ancorados nos seus respectivos repertórios culturais e históricos. Portanto, a ancoragem ajuda a tornar o estranho em informação acessível aos diversos grupos sociais que poderão, assim, reinterpretar e salientar determinados aspectos do assunto, em detrimento de outros. Ademais, a ancoragem permite a construção por parte de indivíduos e grupos de instrumentos de referência em comum para regular a realidade social partilhada.

Existem poucos trabalhos psicossociais para tratar do fenômeno das representações de grupos nacionais e do nacionalismo, enfatizando a importância das estratégias de elaboração discursiva e processos socioculturais de grande escala, das relações intra e intergrupos. Segundo Tajfel, Deutsch (1966, conforme citado por Tajfel, 1969) teria feito uma contribuição fundamental para a teoria psicossocial do nacionalismo ao realizar uma minuciosa análise de como o Estado moderno consegue transformar os seus cidadãos numa comunidade no senso estrito, ou seja, "the collection of living individuals in whose minds and memories the habits and channels of culture are carried" (Tajfel, 1969, p. 166). Para Deutsch (conforme citado por Tajfel, 1969), os elementos partilhados mencionados servem como facilitadores da comunicação e configuram uma comunidade partilhada. Contudo, construir uma comunidade inclui amiúde estabelecer hierarquias entre indivíduos e grupos, uns considerados mais valorizados, outros menos, constituindo maiorias e minorias. Portanto, para as maiorias importa frequientemente assimilar as minorias, o que pode ser obtido pela sistemática persuasão, às vezes com intenções edificantes, de que não vale a pena ser diferente, mostrando os infortúnios decorrentes de pretender estar separado e buscar autonomia. Assim, Guillaumin (1972) realizou uma minuciosa análise da maneira como a imprensa francesa costuma categorizar a minoria, sublinhando os seguintes aspectos: 1) existe um enorme contraste na maneira como a maioria é tratada, em termos gerais e indeterminados, enquanto a minoria em termos específicos, lembrando sempre a sua característica de grupo particular; 2) acontecimentos violentos, como um assassinato, são freqüentemente associados às minorias sociais; 3) a minoria é definida, na sociedade, por sua relação de alteridade com relação ao "eu" padrão ou majoritário; 4) características do sujeito minoritário só aparecerão na imprensa, na medida em que coincidam ou não com os estereótipos; 5) o minoritário está sempre fora, no espaço ou no tempo, ao contrário do majoritário que está aqui e agora, o minoritário tende a pertencer, seja a um passado de glórias, mítico e perdido, seja a um futuro escuro e hostil. Em suma, Guillaumin (1972) concluiu que a norma majoritária é uma forma simbólica que tende a esconder um sujeito social, um grupo implícito que define o conjunto de relações e categorizações intergrupais.

Outro estudo interessante foi o de Windisch (1978), que detectou tendências dualistas de categorização entre nacionalistas na Suíça, os quais representavam a sociedade através dos seguintes recortes: 1) a nacionalidade (suíços contra estrangeiros), tendo como conseqüência uma desvalorização dos estrangeiros; 2) oposição entre os dirigentes e o resto da população, acarretando numa visão moralizante a respeito dos erros dos governantes; 3) oposição entre o normal e o desviante, que provoca a percepção de mudanças como indesejáveis. Mais recentemente, em estudo realizado entre estudantes de sete países europeus (Moscovici \& Perez, 1997), foi encontrada uma correlação positiva entre representações dos ciganos e o tipo de sociedade preferida. Foram propostos três tipos de sociedade: o tipo A, com um grupo majoritário único e exclusivo; o tipo $\mathrm{B}$, com uma maioria e uma minoria; e o tipo $\mathrm{C}$, uma sociedade onde só existem minorias. Os estudantes mostraram preferir sociedades do tipo A $(29,7 \%)$ e B $(21,2 \%)$, as quais estavam associadas a representações negativas sobre os ciganos.

Um passo poderia ser dado se pudéssemos articular as formulações referentes às representações sociais às relações intergrupais em geral.

\section{Algumas teorias psicossociais sobre representações e relações intergrupais}

Procurando as bases sociais e psíquicas para os fenômenos de hostilidade intergrupal, Adorno, Frenkel-Brunswik, Levinson e Sanford (1950), detectaram a presença de indivíduos considerados como portadores de personalidade autoritária: um conjunto de convicções conformistas e de submissão às autoridades e costumes, formado na infância e reforçado pelo entorno social, que criaria uma série de frustrações, posteriormente deslocadas contra os grupos minoritários. A crítica dirigida num certo momento por alguns teóricos da área de relações intergrupais em relação aos estudos de Adorno e cols.(1950), foi a respeito da limitação da dimensão da dinâmica da personalidade individual para explicar a hostilidade intergrupal. Contudo, ao focalizar a dimensão intrapsíquica para explicar a hostilidade a minorias estes estudos tornaram-se, depois do nazifacismo, um marco importante, sobretudo por não considerarem mais, isoladamente, o papel de líderes e do Estado para a produção do fenômeno, incluindo o indivíduo comum e seu entorno social imediato.

Allport (1954), por sua vez, estabeleceu uma conexão teórica entre processos de categorização e desenvolvimento de estereótipos. Segundo este autor, os estereótipos estão associados a emoções e têm natureza seletiva e auto-reforçadora, o que provoca hostilidade a certos estímulos. Para ele, as atitudes xenófobas surgem como resposta a certas situações como a de medo e ansiedade, por exemplo. Ele chamou a atenção sobre a importância de fatores históricos e culturais na escolha de um "bode expiatório", que seria decorrente da reativação de uma série de mitologias e símbolos ancorados numa tradição secular (Allport, 1954, conforme citado por Pettigrew, 1998), propôs as condições para viabilizar um contato intergrupal positivo: 1) status idêntico dos grupos durante o contato; 2) metas em comum; 3) cooperação intergrupal; e, 4) apoio de autoridades, costumes ou leis. Ao que Pettigrew (1998) acrescentou o potencial para conhecimento mútuo (acquaintanceship potencial).

Posteriormente, os estudos sobre atitudes nacionais e nacionalismos foram sendo analisados associados ao racismo, como mecanismo defensivo constituído para 
resolver conflitos internos do indivíduo. Contudo, Pettigrew e Meertens (1995) verificaram que na Europa não havia correlação entre racismo e percepção de privação relativa individual, mas intergrupal. Ou seja, se o indivíduo avalia seu grupo como perdendo posição face ao grupo minoritário, ele tende a perceber este último de modo mais explicitamente preconceituoso.

Outros psicólogos sociais estudaram os estereótipos e a categorização social através de métodos experimentais, entre os quais Sherif e Sherif (1969), que analisaram reações de hostilidade entre dois grupos em situação de competição, constatando o papel de metas comuns supra-ordenadas (superordinate goal) para a cooperação. Segundo Tajfel, Flament, Billig e Bundy (1971), em teoria sobre identidade social, os indivíduos comparam, constantemente, as vantagens e desvantagens das suas categorias de pertença. Em pesquisa feita através de matrizes de remuneração, eles descobriram que os sujeitos se sentiram mais atraídos por ganhos de valores relativos que os absolutos, preferindo que o seu grupo ganhasse mais que o outro, mesmo que os valores absolutos a serem recebidos implicassem em redução dos ganhos do seu próprio grupo. Esta teoria foi testada e ampliada (Brown, 2000).

Porém, segundo Moscovici e Paicheler (1978) uma minoria com auto-imagem negativa tem dificuldades para definir fronteiras claras entre intragrupo e extragrupo. Esta situação a torna vulnerável à pressão exercida pela maioria para abandonar seus critérios. No caso de uma minoria com auto-imagem positiva, em contraste, o grupo procura reconhecimento social, o que é diferente da comparação social. Nesse sentido, Moscovici (1979) menciona dois tipos de minoria que se ajustam aos grupos nacionais e étnicos em foco. As minorias podem desafiar a ordem bancando um processo de inovação/resistência dentro do sistema social. As características de uma minoria ativa, autora de um processo de influência social, seriam as seguintes: oposição consciente à norma majoritária e manutenção coerente da contra-norma em conflito aberto com a maioria. Assim, no plano internacional os indivíduos pertencentes a países secundários em termos de competição, como Espanha e Brasil, tendem a apresentar uma postura ambivalente, simultaneamente, destratando e/ou mostrando identificação com os valores preconizados por potências hegemônicas como os EUA. Já no plano interno de um país hierarquizado em termos étnico-raciais como o Brasil, os grupos minoritários que têm mais consciência quanto a sua diferença cultural tendem a afirmar positivamente seu grupo étnico particular e o de outros.

Ao lado disso, Brewer (1999) defende o argumento de que o viés intragrupal e a hostilidade para com o extragrupo são diferentes e freqüentemente separados. Ela propõe o desenvolvimento de emoções positivas e de uma identidade complexa em que indivíduos teriam ligações com diferentes grupos identitários, o que se poderia atingir em sociedades menos segmentadas e hierarquizadas. Mesmo assim, Brown (2000) enfatiza a importância, principalmente para as minorias, do reconhecimento da necessidade de ter e manter a sua diferença identitária. O que pode esbarrar, segundo o mesmo autor, em dificuldades de convencer os grupos majoritários das vantagens de tal redefinição.

Os estudos de relações intergrupais, apresentados anteriormente, buscaram os seus princípios gerais nem sempre incluindo e articulando os aspectos sociais elaborados pela antropologia, história e o campo das representações sociais.

\section{Representações de grupos nacionais no Brasil}

No Brasil, Freyre (1963) constatou a influência exercida pela cultura moura nos costumes do Brasil colonial e sublinhou o ódio ao mouro como traço profundo que afetou o português e o predispôs ao nacionalismo e ao imperialismo. Ribeiro (1970), por sua vez, viu no Brasil uma "Roma tropical" fruto da miscigenação de negros, índios e portugueses, mas onde o grupo latino-português resistiu à desintegração; "para impor sua língua e seu perfil cultural básico às novas etnias que faria nascer" (Ribeiro, 1970, p. 99).

A sociedade brasileira é um universo complexo e composto por vários grupos com características mais ou menos diferenciadas. Segundo a abordagem das representações sociais, cada grupo constrói as suas representações do Brasil e de outros países de acordo com referenciais históricos e culturais particulares. Assim, podemos supor que a autodenominação étnica seja uma condição de produção relevante. Isto é, parecem existir psicossocialmente no Brasil três grupos étnico-raciais autodefinidos importantes: negros, morenos e brancos, os quais pensam e interpretam a realidade contemporânea baseando-se em experiências e construções culturais e históricas passadas e, cada um deles, possui e divulga estas representações numa dinâmica contínua de incorporação de novas informações sem alterar as bases ou significados de longa durabilidade histórica. Entretanto, segundo MoritzSchwartcz (1998), o censo de 1976 do IBGE consolidou a concepção de que entre os brasileiros a identidade racial é mais uma questão de marca do que de origem no sentido literal, diferente dos EUA onde, independente do fenótipo do indivíduo, o que prevalece é a origem do mesmo. Assim, os brasileiros se atribuíram 136 tipos de cor, apesar de 57\% se considerarem brancos, negros, indígenas, amarelos e pardos. Contudo, a autora observou que havia entre as várias tonalidades a tendência forte de branqueamento, além da existência de estereótipos raciais. Na sua visão, a cor seria usada individualmente como uma forma de construção do eu-social em função dos vários contextos de interação. Assim, seria importante compreender melhor como os que se autodefinem como negros, brancos e morenos representam e vivem diferentes assuntos/objetos sociais relevantes (Carone \& Bento, 2002). Mas, é bom notar que nos EUA a autodenominação teve um papel importante na construção grupal étnica, tal como Philogène (1999) foi capaz de mostrar em trabalho recente sobre a busca de reconhecimento social do grupo negro ao substituir a expressão Black por African-American, considerada mais positiva entre os diferentes grupos. Portanto, a consolidação da democracia na sociedade brasileira recente pode estar estimulando na esfera pública a construção e difusão de denominações étnico-raciais grupais partilhadas, tal como parece ser o caso de indivíduos de origem afro-brasileira que têm se autodefinido cada vez mais como "negros". Nesse sentido, a constituição de uma nacionalidade brasileira tem como possibilidade a construção de formas, seja de reconhecimento de diferenças e autonomias históricas de diferentes grupos particulares que compõem a sociedade, seja de uniformidades nacionais (Leite, 1976) em torno de 
grupos particulares dominantes, como foi a experiência histórica de outros países, sobretudo europeus (Hobsbawn, 1990/1997), tornando-se momento/critério importante para se avaliar a influência social relativa dos grupos. Ou seja, há os que acreditam que no Brasil coexistem várias culturas, assim como, de que existe tendência de apagamento/silenciamento de outras. Contudo, a suposição mais segura parece ser a de que a realidade de coexistência de representações na sociedade não implica que uma delas não possa ser considerada como mais influente ou hegemônica e oferecida como modelo coletivo. Ao lado disso, entendemos que o negro seja o grupo que possui modelos culturais e históricos mais distintos e separados em relação aos do branco. É de se esperar, portanto, que o negro represente os grupos nacionais de maneira mais autônoma em relação aos padrões hegemônicos, já que ele se inspiraria menos do que os outros grupos numa representação centralizada e hierárquica das relações internacionais, devido aos comportamentos socioculturais de resistência ancorados/objetivados em modelos afro-brasileiros antigos, assim como a uma maior focalização no indivíduo/grupo particular e, enfim, devido a certa influência islâmica experimentada no passado por alguns dos grupos dos quais descendem. $\mathrm{O}$ moreno, ao contrário, deve se caracterizar por maior adesão aos valores preconizados pelo grupo branco, o que o tornaria um grupo híbrido que, no seu conjunto, dificilmente logra comunicar representações específicas do seu grupo. É possível que esta dificuldade do moreno esteja relacionada ao processo de assimilação mais acentuado de índios e parte dos negros à cultura branca, criando expectativas de integração ou promoção social muitas vezes não realizadas, em detrimento de suas diferenças socioculturais.

Enfim, consideramos que, apesar de uma história européia de conflitos entre cristãos e muçulmanos, experiências recentes de contato entre brasileiros e povos árabes/muçulmanos no Brasil afetaram as representações históricas sobre os mesmos, favorecendo uma representação mais neutra e, às vezes, favorável do extragrupo em esferas consideradas menos estratégicas para os grupos dominantes.

Sumarizando, podemos supor a partir da revisão seletiva e sucinta de três conjuntos de campos teóricos (representações sociais, relações intergrupais e ciências sociais) acima apresentada que, em função de pertencerem a um grupo de situação dominante na sociedade brasileira, os "brancos" tenderão a representar os grupos nacionais Brasil, EUA e países árabes/muçulmanos segundo a perspectiva nacionalista, que busca dimensões nos extragrupos que permitam comparabilidades favoráveis para o intragrupo (Brasil) e desfavoráveis para o extragrupo (EUA e países árabes/muçulmanos), usando uma linguagem genérica/supragrupal e enfatizando as lideranças políticas como principal agente de mudança da nação, em contraste com a tendência de considerar as respectivas sociedades em termos de indivíduos/grupos particulares (minorias étnico-raciais vistas mais como infortunadas economicamente) a partir de dimensões desfavoráveis. Enquanto os "negros" tenderão a representar os mesmos grupos nacionais segundo a perspectiva minoritária ativa, que busca a afirmar indivíduos/grupos particulares nacionais, focalizando mais as dimensões favoráveis destes últimos. Enfim, os "morenos" tenderão a apresentar um perfil representacional/intergrupal misto, apesar de esperarmos maior adesão ao posicionamento dos "brancos" nos assuntos mais cruciais para este grupo.

\section{Método}

\section{Participantes}

Foram 219 estudantes de segundo grau da rede pública de ensino no Rio de Janeiro, os quais se definiram como negros $(n=31)$, morenos $(n=88)$ e brancos $(n=100)$. É preciso dizer que a forma de autodefinição étnica no Brasil, sobretudo para os grupos não brancos, é usualmente verbalizada através da dimensão racial, ainda que esta recubra outros conteúdos, como os étnicos e psicossociais, estes mais visados por esta pesquisa.

\section{Instrumento e procedimento}

Um questionário foi elaborado para permitir-nos observar representações sobre o Brasil, os EUA e os países árabes/muçulmanos entre estudantes do Rio de Janeiro. A escolha dos países mencionados está relacionada à problemática básica da pesquisa que contrapõe grupos autodefinidos majoritários (brancos), minoritários (negros) e intermediários (morenos), adotando representações/relações intergrupais nacionalistas versus afirmação de indivíduos/grupos particulares nacionais (Brasil); em seguida, temos países que serviram como forma complementar de observação, permitindo-nos acessar representações/relações intergrupais: um, de status majoritário internacional (EUA) e, outros, minoritários (Países árabes/muçulmanos). Já a escolha da denominação "países árabes/muçulmanos" decorreu do fato de serem um conjunto de países que partilham a mesma língua e muitos dos quais a mesma religião, sendo amiúde categorizados assim na imprensa brasileira. A escolha atendia à tendência observada, de se tratar de países pouco conhecidos e quase todos incapazes de gerar a representação socialmente mais consolidada em torno das noções contidas no par árabe/muçulmano. No caso dos EUA, é preciso lembrar que não só foi o primeiro país a reconhecer o Brasil depois de sua independência, como veio a se tornar alvo de representações hostis em função do nacionalismo interno e de movimentos antiimperialistas internacionais.

Para conhecer as representações do Brasil foi criada uma situação simulada em que o estudante foi solicitado a escrever uma carta apresentando o Brasil para um colega estrangeiro. Também solicitamos aos estudantes que imaginassem uma viagem aos EUA e escrevessem o que eles iriam encontrar lá. Já em relação aos países árabe/muçulmanos, preparamos uma situação em que os participantes imaginariam terem recebido um prêmio para viajar gratuitamente para os mesmos países, sobre os quais escreveriam o que esperariam encontrar lá. Enfim, o questionário também conteve perguntas sobre dados pessoais e a questão de como ele/ela se autodefinia em termos étnicos e raciais. Ou seja, solicitamos que os participantes se autodefinissem livre e espontaneamente em termos étnico-raciais. Houve maior tendência de resposta em termos raciais branco, moreno (moreno, moreno escuro) e negro (preto, escuro) e de traços supra e infragrupais, como região do país, estatura, os quais foram excluídos em função 
da baixa frequiência. Os estudantes responderam o questionário em local de estudo e em situação coletiva durante o primeiro semestre de 2001.

\section{Análise de dados}

Os dados foram ordenados em tabelas de frequiência e percentagem após análise de conteúdo de tipo categorial de temas (Bardin, 1991). Tratou-se de reunir palavras, frases e outras formas verbais, segundo o significado comum manifesto. Ademais, cada tema encontrado foi classificado em função de sua atitude favorável, desfavorável ou neutra em relação ao país representado. Em seguida, foram realizados testes de qui-quadrado comparando as diferenciações/ aproximações temáticas entre os grupos de autodefinição étnica-racial. Na comparação entre os grupos, quando a percentagem do tema e/ou atitude foi de pelo menos de $25 \%$ acima dos demais grupos foi relatada por indicar diferenciação social. Abaixo expomos ilustrações de temas usados para representar Brasil, EUA e países árabes/muçulmanos, seguidas de indicações segundo sexo (masculino $=\mathrm{m}$; feminino $=\mathrm{f}$ ), idade e autodefinição étnica/racial: negro $(\mathrm{N})$, moreno (M) e branco (B).

\section{Temas sobre Brasil (BR), EUA (EUA) e países árabes/ muçulmanos (PAM)}

Desenvolvimento econômico em geral: temas que fizeram menção à esfera econômica (indústria, tecnologia, emprego, comércio, consumo, etc., enfim, elementos que simbolizam o grau de desenvolvimento ou dinamismo econômico em seu conjunto). "é um país em vias de desenvolvimento apesar de estar localizado na América Latina (Hemisfério Sul)” (BR) $(\mathrm{m}, 18, \mathrm{~N})$ "um país muito avançado em sentido tecnológico" (EUA) (f, 16, M); “um país hiper-desenvolvido!"(EUA) (f, $16, \mathrm{~B})$ "um povo totalmente subdesenvolvido" (PAM) (m, $16, \mathrm{M})$.

Desenvolvimento econômico em particular: temas que enfatizaram a situação econômica no âmbito da sociedade, ressaltando aspectos vividos em termos comportamentais/ mentais: "Nos ajude, por favor!” (BR) (f, 17, M); "Barrigas cheias de vermes (...). Miseráveis que lutam para sobreviver" (BR) (f, 15, B); " lá desde o mais pobre, ao mais rico tem uma vida digna" (EUA) (f, 28, B); "Fome e miséria" (PAM) (f, 16, B).

Cultura: temas tratando de idioma, costumes, diferenças, estranhezas, exotismos, comida, religião, artes, lugares e monumentos históricos, entre outros: "O Brasil é o país do samba e do futebol, mesmo em meio a tanta dificuldade nunca deixamos de sorrir" (BR) (f, 18, N); "tem os melhores artistas e cantores do mundo" (EUA) (f, 14, N); "Encontraria o Mickey e a turma dele” (EUA) (f, 19, M); “com costumes diferentes mas interessante"(EUA) "muito quibe” (PAM) (m, 18, M); “O Egito,(...), com suas esfinges, sarcófagos e múmias guardam grandes segredos no Oriente” (PAM) (f, 16, B); “(...) com a cultura definida pela religião, que é levada muito a sério por eles" (PAM) (m, 17, B); "Pessoas com outros estilos de vida e outros costumes. Eu iria adorar !!!” (PAM) (f, 19, N); “barbaridades tidas como 'diferenças culturais'” (PAM) (f, 16, B).
Educação/saúde: temas sobre educação, saúde, qualidade de vida e esporte: "falta de médicos" (BR) (f, 13, M); "E gostaria de estudar lá. Para quando eu for prestar concurso eu esteja bem qualificada” (EUA) (f, 16, M); “muitas vezes nem sabem onde se localiza o Brasil” (EUA) (m, 16, B); "Os jovens são muito ligados à aparência, deixando de lado outras coisas importantes, como a educação” (EUA) (f, 16, $\mathrm{B})$; "pessoas analfabetas" (PAM) (f, 16, M); "Bando de doentes servindo a um suposto 'Deus' que (se existisse) não dá a mínima para esses raquíticos que se acham guerreiros" (PAM) (m, 15, B).

Cidadania: temas sobre direitos humanos, justiça, denúncias a respeito de agressão ao ecossistema, exclusão: "ainda tenho esperança de um dia sejamos um só povo sem exclusões” (BR) (f, 17, N); “o povo é muito unido mas tem preguiça de lutar pelos seus direitos" (BR) (m, 16, M); “com muito mais (...), respeito e até talvez segurança” (EUA) (f, 17, $\mathrm{N})$; "mulheres sendo maltratadas ao invés de ter carinho" $(P A M)(\mathrm{m}, 17, \mathrm{~N})$; "pessoas (...) sem liberdade de expressão" (PAM) (m, 16, M).

Estado/sociedade: temas sobre corrupção, ordem ou caos urbano, declaração de sentimento nacional ou etnocentrismo por meio de símbolos como a bandeira nacional ou afirmação da identidade brasileira, constatação do poder que um Estado ou nação exerce sobre outro, como dominação econômica, política ou militar: "os políticos só sabem roubar dinheiro do povo, na televisão só mostra a corrupção” (BR)” (m, 17, $\mathrm{M})$; "acho que está faltando um pouco de patriotismo por parte da população, que não se interessa pela melhora de sua nação” (BR) (f, 15, B); “o seu próprio povo não tem consciência do seu potencial” (BR) (f, 15, B); "País que se acha malandro e muito ambicioso" (EUA) (m, 16, B); "exploram o Brasil que aos poucos vai ficando mais pobre" (EUA) (f, 16, B); "Muitas guerras religiosas e territoriais" (PAM) (m, 14, B).

País em geral: temas gerais sobre o país, ou seja, avaliação positiva ou negativa sem mencionar seus grupos específicos; "O Brasil é um país bom, com alguns problemas como qualquer lugar" (BR) (f, 16, M); “o Brasil é um país maravilhoso" (BR) (f, 18, N); “Os Estados Unidos, para mim seria o máximo” (EUA) (m, 14, M); "Acho que é um lugar como todos têm seus encantos seus defeitos mais legal” (EUA) (f, 17, N).

País em particular: temas sobre avaliações sobre o país, ressaltando a realidade existencial e cotidiana de diversos grupos específicos e suas diferenças culturais e de vida: "Ai você da África, sou negro e me orgulho de minha raiz África” (BR) (m, 17, N); "ainda que camuflado existe muito racismo" $(B R)(\mathrm{m}, 17, \mathrm{~N})$; "As mulheres são livres e vivem bem à vontade" (BR) (f, 19, N); "o funk está entrando na casa de todos, (...)(uma vergonha)" (BR) (f, 17, M); "certo preconceito racial em algumas cidades” (EUA) (m, 16, N); "encontraria também preconceito por parte do povo por conta se ser um ocidental e de não aceitar a sua religião" $(P A M)(\mathrm{m}, 18, \mathrm{~N})$.

Indivíduo em geral: temas sobre atributos individuais considerados mais gerais na sociedade, como inteligência e beleza física: "sem contar das meninas lindas que há por aqui” (BR) (f, 16, M); “Odeio os Estados Unidos. Encontraria muitos americanos gordos, brancos” (EUA) (f, 16, B); 
"Um montão de pessoas feias” (PAM) (f, 17, B); “estupidez humana" (PAM) (m, 15, B).

Indivíduo em particular: temas sobre indivíduos com comportamentos/mentalidades considerados inerentes à sua particularidade e singularidade, ressaltando auto-afirmação do eu-individual ou empenho em construir um itinerário próprio que visa autonomia social: "responde pelos seus próprios atos" $(B R)(\mathrm{f}, 17, \mathrm{~N})$; "Eu acho que se tivéssemos mais pessoas (...), com vontade de vencer" $(B R)(\mathrm{f}, 18, \mathrm{~N})$; "encontraria pessoas diferentes e com mais vontades próprias" (EUA) (f, 15, N).

Indivíduo face às normas: temas sobre normas morais/ éticas mais gerais na sociedade, como criminalidade, violência, desvio ou cumprimento das mesmas: "mas também temos muita prostituição e drogas" (BR) (f, 15, M); "eu acho muito perigoso lá. (...) mais bandidos nas ruas" (EUA) (m, 14, B); "uma porção de anormal andando de camelo" $(P A M)(\mathrm{m}, 16, \mathrm{M})$.

Natureza: temas sobre paisagem, mar, praia, deserto, etc.: "o Brasil é um país lindo, praias espetaculares, grandes cidades, lagoas, parques, etc.” $(B R)(\mathrm{m}, 14, \mathrm{~N})$; “o Brasil é maravilhoso por parte de sua fauna e flora” " $(B R)(\mathrm{m}, 16, \mathrm{M})$; "Frio e muita neve!" (EUA) (m, 16, M); "um calor horrível" (PAM) (f, 17, M); "muita areia e nunca iria achar água pois lá não existe água para beber, iria morrer de sede" (PAM) (f, 19, M); "acho que encontraria belezas que nunca vi" $(P A M)(\mathrm{m}, 17, \mathrm{~N})$.

Interações interpessoais: temas a respeito de traços/ comportamentos interpessoais, como simpatia, amizade, ou o contrário: "O Brasil é o país (...) com as pessoas mais calorosas e simpáticas” (BR) (f, 17, M); “nós brasileiros somos as pessoas mais solidárias desse mundo" $(B R)(\mathrm{f}, 15$, B); "tem um povo muito individualista" (EUA) (m, 16, B); "Iria encontrar pessoas frias e isoladas" (EUA) (m, 17, B); "coisas simples como carinho, amor e compreensão, ficaram esquecidas" (EUA) (f, 19, B); "Um país fechado (triste, pesado, antipático)" (PAM) $(\mathrm{m}, 15, \mathrm{~N})$; “fazer novos amigos" (PAM) (f, 17, N).

\section{Resultados}

Na pesquisa sobre representações de nações entre estudantes do Rio de Janeiro, todos os grupos étnico/raciais autodefinidos representaram o Brasil e os EUA de maneira mais favorável do que os países árabes/muçulmanos. Do mesmo modo, o negro, o moreno e o branco coincidiram em atitudes mais desfavoráveis sobre países árabe/muçulmano.

Vamos relatar os temas mais utilizados (relataremos os três relativamente mais usados e acima de $4 \%$ ) em geral. Em relação ao Brasil (Tabela 1), os negros se referiram mais à "natureza", "desenvolvimento econômico geral", "país em particular". Os morenos, se sobressaíram em aspectos ligados ao "país em geral", "indivíduo face às normas", "relações interpessoais", "indivíduo em geral”. Já os brancos, apresentaram mais temas em "Estado/sociedade", "país em geral", "relações interpessoais". Ademais, o negro apresentou mais temas favoráveis do que o moreno e o branco em relação ao Brasil ( $\chi^{2}$ (Favoráveis) $=64,82 ; g l=24 ; p<$ $0,01)$, nos seguintes aspectos: "natureza", "desenvolvimento econômico geral", "país em particular", "indivíduo em

Tabela 1. Temas sobre o Brasil, os Estados Unidos e os países árabes-árabes/muçulmanos, segundo grupo étnico-racial autodefinido

\begin{tabular}{|c|c|c|c|c|c|c|c|c|c|}
\hline \multirow{3}{*}{ Temas } & \multicolumn{9}{|c|}{ Países / Grupo étnico-racial autodefinido } \\
\hline & Brasil & Brasil & Brasil & EUA & EUA & EUA & PAM & PAM & PAM \\
\hline & Negro & Moreno & Branco & Negro & Moreno & Branco & Negro & Moreno & Branco \\
\hline Desenvol. econômico geral & 8,67 & 5,34 & 5,01 & 16,98 & 25,00 & 24,11 & - & 4,45 & 2,55 \\
\hline Desenvol. econômico particular & 2,31 & 4,45 & 7,41 & 1,88 & 2,00 & 1,77 & 8,64 & 11,38 & 14,23 \\
\hline Cultura & 4,62 & 5,12 & 3,60 & 17,92 & 9,33 & 10,15 & 40,74 & 33,66 & 37,22 \\
\hline Educação/saúde & 4,62 & 4,45 & 4,60 & 0,94 & 5,00 & 3,55 & 2,46 & 0,99 & 2,18 \\
\hline Cidadania & 6,35 & 6,90 & 5,61 & 5,66 & 2,66 & 2,03 & 9,87 & 4,45 & 6,20 \\
\hline Estado/sociedade & 6,35 & 9,35 & 14,82 & 3,77 & 7,33 & 15,22 & 3,70 & 6,43 & 6,56 \\
\hline País em geral & 10,98 & 14,47 & 13,02 & 14,15 & 8,66 & 6,59 & 3,70 & 3,46 & 2,18 \\
\hline País em particular & 5,78 & 2,67 & 1,40 & 8,49 & 3,66 & 2,53 & 3,70 & 0,49 & 1,09 \\
\hline Indivíduo em geral & 4,04 & 6,45 & 4,60 & 3,77 & 4,33 & 7,61 & 4,93 & 8,41 & 7,66 \\
\hline Indivíduo em particular & 5,20 & 2,00 & 0,80 & 1,88 & - & 0,76 & - & - & 0,36 \\
\hline Indivíduo face às normas & 7,51 & 10,02 & 7,01 & 6,60 & 11,33 & 7,86 & - & 3,46 & 2,91 \\
\hline Natureza & 27,16 & 18,93 & 21,84 & 10,37 & 11,66 & 6,85 & 4,93 & 9,90 & 6,56 \\
\hline Interações interpessoais & 1,73 & 8,46 & 9,41 & 3,77 & 6,66 & 9,64 & 13,58 & 7,92 & 8,39 \\
\hline Não responde & 4,62 & 1,33 & 0,80 & 3,77 & 2,33 & 1,26 & 3,70 & 4,95 & 1,45 \\
\hline Outros & - & - & - & - & - & - & - & - & 0,36 \\
\hline
\end{tabular}

Nota 1: Os valores representam percentagens de temas sobre o Brasil, segundo grupo étnico-racial autodefinido. $\chi^{2}$ (comparação entre os grupos negro, moreno e branco em relação aos temas listados) $=77,55 ; g l=26 ; p<0,01$.

Nota 2: Os valores representam percentagens de temas sobre os Estados Unidos da América, segundo grupo étnico-racial autodefinido. $\chi^{2}$ (comparação intergrupal sobre os temas listados) $=68,16 ; g l=26 ; p<0,01$.

Nota 3: Os valores representam percentagens de temas sobre países árabes/muçulmanos, segundo grupo étnico-racial autodefinido. $\chi^{2}$ (comparação intergrupal segundo temas listados) $=32,50 ; g l=28$; não significativo. 
Tabela 2. Temas sobre o Brasil, segundo grupo étnico-racial autodefinido e atitudes favoráveis e desfavoráveis

\begin{tabular}{|c|c|c|c|c|c|c|}
\hline \multirow{3}{*}{ Temas } & \multicolumn{6}{|c|}{ Grupo étnico-racial autodefinido / atitudes } \\
\hline & Negro & Negro & Moreno & Moreno & Branco & Branco \\
\hline & Favor. & Desfav. & Favor. & Desfav. & Favor. & Desfav. \\
\hline Desenvolvimento econômico geral & 8,7 & 10,1 & 3,2 & 8,5 & 3,4 & 7,8 \\
\hline Desenvolvimento econômico particular & - & 6,7 & - & 10,6 & 1,0 & 17,8 \\
\hline Cultura & 6,7 & - & 6,9 & 2,6 & 5,5 & 0,5 \\
\hline Educação/saúde & 1,9 & 8,4 & 1,2 & 7,4 & 4,8 & 3,6 \\
\hline Cidadania & 1,9 & 15,2 & 3,2 & 12,2 & 2,0 & 11,5 \\
\hline Estado/sociedade & 3,8 & 11,8 & 4,9 & 14,9 & 8,9 & 24,6 \\
\hline País em geral & 8,7 & 15,2 & 14,3 & 14,4 & 13,8 & 12,5 \\
\hline País em particular & 7,7 & 3,3 & 1,6 & 3,2 & 1,0 & 0,5 \\
\hline Indivíduo em geral & 4,8 & 3,3 & 10,6 & 1,6 & 6,2 & 2,6 \\
\hline Indivíduo em particular & 6,7 & 3,3 & 3,6 & - & 1,3 & - \\
\hline Indivíduo face às normas & - & 22,0 & 0,8 & 22,9 & 0,6 & 17,2 \\
\hline Natureza & 45,6 & - & 34,4 & - & 35,2 & $\mathbf{1 , 0}$ \\
\hline Interações interpessoais & 2,9 & - & 14,7 & 1,0 & 15,5 & - \\
\hline
\end{tabular}

Nota 1: Os valores representam percentagens de temas sobre o Brasil, segundo grupo étnico-racial autodefinido, em termos favoráveis e desfavoráveis. $\chi^{2}$ (comparação entre os grupos negro, moreno e branco para os temas favoráveis ) $=64,82 ; g l=24 ; p<0,01 \cdot \chi^{2}$ (comparação intergrupal de temas desfavoráveis) $=44,88 ; g l=24 ; p<0,01$.

Nota 2: A comparação de temas neutros através do teste de qui-quadrado foi não significativa.

Tabela 3. Temas sobre os Estados Unidos e os países árabes-árabes/muçulmanos, segundo grupo étnico-racial autodefinido e atitudes favoráveis e desfavoráveis

\begin{tabular}{|c|c|c|c|c|c|c|c|c|c|c|c|c|}
\hline \multirow{4}{*}{ Temas } & \multicolumn{12}{|c|}{ Países / Grupo étnico-racial autodefinido / atitudes } \\
\hline & EUA & EUA & EUA & EUA & EUA & EUA & PAM & PAM & PAM & PAM & PAM & PAM \\
\hline & Negro & Negro & Moreno & Moreno & Branco & Branco & Negro & Negro & Moreno & Moreno & Branco & Branco \\
\hline & Favor. & Desfav. & Favor. & Desfav. & Favor. & Desfav. & Favor. & Desfav. & Favor. & Desfav. & Favor. & Desfav. \\
\hline Desenv. econ. geral & 28,1 & - & 34,5 & 8,2 & 40,2 & 4,3 & - & - & 5,4 & 5,7 & 8,7 & 1,2 \\
\hline Desenv. econ. par. & - & 5,5 & 1,0 & 4,1 & 2,2 & 1,4 & - & 16,6 & - & 22,1 & 3,5 & 22,6 \\
\hline Cultura & 25,0 & 5,5 & 11,7 & 4,1 & 6,7 & 10,0 & 57,8 & 23,8 & 48,6 & 21,1 & 47,3 & 24,5 \\
\hline Educação/saúde & 1,5 & - & 6,9 & 2,0 & 3,6 & 4,3 & - & 4,7 & - & 1,9 & - & 3,7 \\
\hline Cidadania & 6,2 & 5,5 & 1,0 & 6,1 & 1,3 & 3,5 & - & 19,0 & 2,7 & 7,6 & - & 10,6 \\
\hline Estado/sociedade & 3,1 & 5,5 & 8,5 & 6,1 & 14,0 & 17,2 & - & 7,1 & - & 11,5 & 5,2 & 9,4 \\
\hline País em geral & 14,0 & 13,8 & 8,5 & 8,2 & 6,3 & 5,0 & 10,5 & 2,3 & 2,7 & 3,8 & 3,5 & 2,5 \\
\hline País em particular & - & 25,0 & - & 11,3 & 0,4 & 5,0 & - & 7,1 & - & - & - & 1,2 \\
\hline Indivíduo em geral & 1,5 & 8,3 & 4,2 & 4,1 & 4,5 & 12,2 & 5,2 & 4,7 & 18,9 & 6,7 & 8,7 & 7,5 \\
\hline Indivíduo em part. & 3,1 & - & - & - & 1,3 & - & - & - & - & - & - & - \\
\hline Indiv. face às normas & - & 19,4 & 6,9 & 21,6 & 5,4 & 13,6 & - & - & 2,7 & 5,7 & - & 5,0 \\
\hline Natureza & 14,0 & 5,5 & 13,8 & 8,2 & 10,4 & 1,4 & 10,5 & - & 13,5 & 9,6 & 15,7 & 3,7 \\
\hline Interações interpes. & 3,1 & 5,5 & 2,6 & 15,4 & 3,1 & 21,5 & 15,7 & 14,2 & 5,4 & 3,8 & 7,0 & 7,5 \\
\hline
\end{tabular}

Nota 1: Os valores representam percentagens de temas sobre os Estados Unidos da América, segundo grupo étnico-racial autodefinido, em termos favoráveis e desfavoráveis. $\chi^{2}$ (comparação intergrupal de temas favoráveis) $=53,51$.; $g l=24 ; p<0,01 \cdot \chi^{2}$ (comparação intergrupal de temas desfavoráveis) $=51,73$; $g l=22 ; p<0,01$.

Nota 2: Os valores representam percentagens de temas sobre os países árabes-árabes/muçulmanos, segundo grupo étnico-racial autodefinido, em termos desfavoráveis. $\chi^{2}$ (comparação intergrupal de temas desfavoráveis) $=36,38 ; g l=22 ; p<0,05$. Os temas neutros sobre os EUA e países árabes/muçulmanos apresentados pelos grupos étnico-raciais autodefinidos foram objeto de teste de qui-quadrado e os resultados foram não significativos.

particular”. O moreno, por sua vez, foi mais favorável em "relações interpessoais", "país em geral”, "indivíduo em geral”. Enfim, o branco mostrou temas mais favoráveis em "interações interpessoais", "país em geral”, "Estado/sociedade". Além disso, o negro mostrou-se mais desfavorável ao abordar os temas "indivíduo face às normas", "cidadania”, "educação/saúde”. O moreno foi desfavorável em "indivíduo face às normas”, “educação/saúde”. Já o branco enfatizou desfavoravelmente "Estado/sociedade", "desenvolvimento econômico particular”.
Em relação aos temas sobre os EUA, os negros se referiram mais à "cultura”, "país em geral”, "natureza", "país em particular". Os morenos, por sua vez, destacaram-se em "desenvolvimento material geral", "natureza”, "indivíduo face às normas". Enfim, os brancos mencionaram "desenvolvimento material geral", "Estado/sociedade”, "interações interpessoais". Ademais, o negro representou os EUA de maneira mais favorável do que os outros grupos em "cultura”, "país em geral”, "natureza”. Já o moreno foi mais favorável nos seguintes aspectos: "natureza”, "educação/ 
saúde", "indivíduo face às normas". No caso do branco, as representações mais favoráveis foram em torno de "Estado/sociedade”, “indivíduo face às normas”, “indivíduo em geral”. Por outro lado, o negro mostrou-se mais desfavorável sobre os EUA nos seguintes temas: "país em particular", "indivíduo face às normas", "país em geral”. O moreno, por sua vez, caracterizou-se por maior desfavorabilidade em "indivíduo face às normas", "natureza”, "desenvolvimento econômico geral” Já o branco foi mais desfavorável em "interações interpessoais”, "Estado/sociedade”, "indivíduo em geral”

Quanto aos temas sobre países árabes/muçulmanos, o negro os descreveu mais em "interações interpessoais”, "cidadania”. Em geral, o moreno se referiu mais a aspectos de "natureza”, “indivíduo em geral”. Enfim, encontramos consenso entre os grupos ao avaliarem o árabe/muçulmano, optando pela descrição de aspectos da "cultura", assim como entre morenos e brancos quanto a "indivíduo em geral" $e$ “Estado/sociedade”. Em relação às atitudes a respeito dos países árabes/muçulmanos, o negro mostrou-se mais favorável ao tratar de "interações interpessoais", "país em geral”. O moreno, por sua vez, tendeu a ser mais favorável em "indivíduo em geral", "natureza" e, o branco, "natureza”, "desenvolvimento econômico geral”, "Estado/sociedade”. Enfim, o negro destacou-se em temas desfavoráveis em “cidadania”, “interações interpessoais”, "país em particular"; o moreno e o branco em "desenvolvimento econômico particular", "estado/sociedade”, “indivíduo em geral”, sendo que o moreno apresentou mais freqüências em temas desfavoráveis sobre "natureza”.

\section{Discussão}

Pretendíamos verificar se os grupos étnicos/raciais teriam representações particulares sobre os grupos nacionais propostos. Assim, consideramos que os dados expostos confirmaram, ainda que parcialmente, a nossa hipótese de diferenciação intergrupal, sobretudo entre os negros em relação aos demais grupos. Vamos tentar interpretar os dados para levantar novas hipóteses de trabalho futuro.

Primeiro, cabe salientar a maior preocupação de morenos e brancos com a situação do Brasil em termos de desenvolvimento econômico. Ou seja, diante dos valores dominantes que colocam o desenvolvimento econômico no topo, o moreno e o branco consideraram mais prudente omitir o aspecto do "desenvolvimento econômico geral" nas suas representações sobre o Brasil. Assim, eles pareceram ser mais vulneráveis ou incertos quanto à avaliação externa que se faz sobre o Brasil nesses assuntos. Ao contrário, o negro mostrou-se favorável em relação ao desenvolvimento econômico geral do Brasil, demostrando ser capaz de construir e manter uma visão diferenciada. Trata-se antes de tudo de um modo de elaborar o problema, segundo cada grupo observado. Aparentemente, para os brancos e os morenos, o desenvolvimento econômico é visto, sobretudo, a partir dos seus efeitos negativos, como se adotassem o ponto de vista dos países mais desenvolvidos. Além disso, consideramos que a atitude de defesa de "Estado/sociedade", assim como a "favorabilidade" na representação das "interações interpessoais”, estariam relacionadas a um projeto de mobiliza- ção nacionalista, principalmente preconizado por brancos, onde se almejaria envolver os grupos negro e moreno. No Brasil, segundo Sérgio Buarque de Holanda (1936/1984), o modelo de relações interpessoais que prevaleceu teria como função socializar os grupos, criando um clima de "intimidade" entre pertencentes a diversas culturas, os quais socializam e convivem sem conflitos aparentes, já que a dimensão grupal não é salientada nas interações. Tais relações interpessoais baseadas na transposição de dinâmicas da vida familiar para a esfera pública, ajudam a reforçar formas de convívio baseadas no desejo de intimidade e numa ética de fundo emotivo (Buarque de Holanda, 1936/1984), práticas de socialização em que os indivíduos pertencentes aos grupos negro e moreno seriam incluídos ao nível interpessoal. Isso acontece porque, através destas práticas de socialização os grupos minoritários são invisibilizados, permanecendo sem chances de reconhecimento/promoção individual e, muito menos, grupal. É desta maneira que, no Brasil, o modelo de relação intergrupal mais preconizado é, na realidade, o interpessoal, tendendo o aspecto grupal a ser esvaziado. Deste modo, podemos afirmar que a ideologia em prol das "interações interpessoais", por enquanto tem sido insuficiente para promover tanto a mobilidade quanto o movimento social de negros/morenos no Brasil. O negro, consciente da diluição da autonomia dos grupos que se dá, sobretudo, através da imersão nas dinâmicas interpessoais, tenta fortalecer uma atitude mais individual aos membros do seu grupo, procurando compensar a fragilidade dos movimentos sociais existentes na esfera pública que incluem como prioritária a questão racial-étnica. Enfim, consideramos que o modelo de "homem cordial" formalizado por Buarque de Holanda (1936/1984) serve, principalmente, para compreender a maneira como o branco brasileiro se vê e procura integrar os outros grupos. Os nossos dados indicaram que, no Rio de Janeiro, muitos negros comunicam, por meio das suas escolhas temáticas e atitudinais, vontade de manter uma fronteira intergrupal mais definida ou busca do reconhecimento de particularidades positivas no país e nos indivíduos. Mesmo assim, também observamos que os negros se destacaram no uso do tema "natureza", freqüente nos demais grupos, podendo servir como aglutinador intergrupal.

Ao lado disso, outros grupos como os morenos têm dificuldades de manter fronteiras grupais definidas, tendendo a se deixar influenciar por crenças, opiniões e discursos do grupo mais influente. Assim, em geral, os morenos se mostraram mais mobilizáveis por diversas dinâmicas de socialização, assim como procuraram saídas mais atenuadoras das diferenças e conflitos intergrupais. É interessante lembrar que o moreno foi quem se mostrou mais preocupado com "indivíduo face às normas". Isto indica que o moreno sofre as conseqüências da forte pressão para ele se integrar à cultura do branco, processo que vem acompanhado de certa tensão, possivelmente provocada por diferenças entre as culturas em contato, assim como por sua desvantagem face a outros grupos. Assim, o moreno não colocou muita ênfase no tema "Estado/sociedade", podendo-se deduzir deste fato que ele se sentia um tanto ausente e afastado em relação ao aparelho estatal e aos discursos nacionalistas mais tradicionais. Em suma, podemos afirmar que, embora ambos os grupos negro 
e moreno tenham que enfrentar problemas comuns, como o racismo e a discriminação, eles apresentaram soluções diferentes para lidar com a cultura dominante. Este contraste de projetos entre negros e morenos, pareceu se refletir, inclusive, na maneira como cada grupo representou o indivíduo, o moreno valorizando mais o "indivíduo em geral" (segundo valores mais aceitos pela cultura dominante, como inteligência e beleza), e o negro procurando o "indivíduo em particular" (ou seja, o indivíduo autônomo e diferente).

Um dado que chama a atenção em relação à representação dos EUA, é que o negro tendeu a mostrar uma atitude mais positiva para com os movimentos sociais e de direitos humanos ("cidadania”) que ocorrem lá do que os outros grupos, o que contrastou com a visão pouco favorável que ele expressou sobre movimentos de “cidadania” no Brasil. Esta valorização da autonomia, particularmente focalizada para o âmbito cultural, é o que permitiria freqüentemente ao negro comparar as culturas e escolher aqueles modelos atitudinais e ideológicos que oferecem alguma possibilidade de desenvolvimento individual e existencial. Já no caso do moreno e as suas representações dos EUA, podemos destacar que, de novo, se distinguiu pela importância dada à “indivíduo face às normas". É que o moreno encontra-se na encruzilhada entre modelos culturais e projetos menos compatíveis, assim como se sentindo como alguém que não pode romper completamente com nenhuma das alternativas. Além disso, o moreno, inversamente ao negro, criticou a prática de cidadania nos EUA, o que parece ser explicável por sua mais estreita adesão ao projeto de construção da nação brasileira, levando-o a duvidar de alguns símbolos centrais da democracia estadunidense, como o desenvolvimento econômico geral, os direitos humanos e a cidadania. O branco, por sua vez, caracterizou-se por uma atitude bastante desfavorável em relação a diversos aspectos da representação dos EUA. Em primeiro lugar, consideramos significativa a atitude mais desfavorável no que se refere à "cultura" dos EUA. Enfim, o tema "interações interpessoais", representado favoravelmente, é considerado pelos brancos um dos pontos frágeis e negativos da sociedade estadunidense.

Em relação às representações de países árabes/muçulmanos, um dos resultados mais destacados foi a tendência de maior abertura intercultural entre os negros, já que estes deram maior importância ao tema "interações interpessoais" do que os outros grupos, como se o negro imaginasse a si mesmo interagindo com árabes/muçulmanos relativamente mais do que com estadunidenses e brasileiros, ainda que nem sempre tenha prevalecido uma representação positiva deste contato. Contudo, consideramos que os dados indicaram que o negro estaria mais disposto a se relacionar de indivíduo para indivíduo com alguns extragrupos, particularmente quando se trata de grupos cujo status é representado como "mais idêntico durante o contato", ou quando existem "metas em comum", condições facilitadoras de um contato intergrupal positivo (Allport, 1954). Além disso, a maior focalizacão do negro nos temas "cidadania" (direitos humanos, etc.) e "país em particular" (grupos étnicos, etc.), que, no caso da representação dos países árabes/muçulmanos foram descritos de forma mais desfavorável por eles, dá a entender que a atenção voltada para a dimensão dos grupos minoritários, da diferença cultural, da autonomia etc. estaria relacionada à abertura intercultural, mais comum entre eles. Já o moreno, criticando a "natureza" dos EUA e dos países árabes/muçulmanos, consideraria a "natureza" um dos pontos centrais do seu enraizamento e gratificação no Brasil. Enfim, observamos uma notável similaridade entre os três grupos étnicos autodefinidos, que representaram o árabe/muçulmano em termos mais culturais, favoráveis e neutros.

Assim, na sociedade brasileira a construção de modelos culturais como autoreferência influente determina a atitude de conformidade ou não em relação a outras estruturas hierárquicas consolidadas no sistema de relações intergrupais internas. A divergência de representações e projetos acentua dificuldades entre os grupos, o que tende a ser atenuado através de discursos conciliadores e algumas omissões.

\section{Referências}

Adorno, T. W., Frenkel-Brunswik, E., Levinson, D. J. \& Sanford, R. N. (1950). The autoritharian personality. New York: Harper.

Allport, G. W. (1954). The nature of prejudice. Cambridge: Addison-Wesley.

Bardin, L. (1991). L'analyse de contenu. Paris: Presses Universitaires de France.

Brewer, M. B. (1999). The psychology of prejudice: Ingroup love or outgroup hate? Journal of Social Issues, 55, 429-444.

Brown, R. (2000). Social identity theory: Past achievements, current problems and future challenges. European Journal of Social Psychology, 30, 745-778.

Buarque de Holanda, S. (1984). Raízes do Brasil. Rio de Janeiro: José Olympio (Originalmente publicado em 1936).

Carone, I. \& Bento, M. A. S. (Orgs.). (2002). Psicologia social do racismo. Estudos sobre branquitude e branqueamento no Brasil. Petrópolis: Vozes.

Freyre, G. (1963). Casa-grande e senzala. Brasília: EdUnB.

Guillaumin, C. (1972). L’idéologie raciste. Paris: Mouton.

Hobsbawn, E. J. (1997). Nations and nationalism since 1780 - programme, myths, reality. Cambridge: Cambridge University Press (Originalmente publicado em 1990).

Leite, D. M. (1976). O caráter nacional brasileiro. (3 ${ }^{\text {a }}$ ed.) São Paulo: Pioneiras.

Moritz-Schwarcz, L. (1998). Nem preto nem branco, muito pelo contrário: Cor e raça na intimidade. Em F. A. Novais \& L. Moritz-Schwarcz (Orgs.), História da vida privada no Brasil (pp.173-244). São Paulo: Companhia das Letras.

Moscovici, S. (1976). La psychanalyse, son image et son public. Paris: Presses Universitaires de France (Originalmente publicado em 1961).

Moscovici, S. (1979). Psychologie des minorités actives. Paris: Presses Universitaires de France.

Moscovici, S. (2000). Representações sociais. Petrópolis: Vozes.

Moscovici, S. \& Paicheler, G. (1978). Social comparison and social recognition: Two complementary processes of identification. Em H. Tajfel (Org.), Differentiation between social groups (pp. 251-266). London: Academic Press.

Moscovici, S. \& Perez, J. A. (1997). Representations of society and prejudices. Papers on Social Representations, 6(1), 27-36.

Pettigrew, T. F. (1998). Intergroup contact theory. Annual Review of Psychology, 49, 65-85. 
Pettigrew, T. F. \& Meertens, R. W. (1995). Subtle and blatant prejudice in Western Europe. European Journal of Social Psychology, 25, 57-75.

Philogène, G. (1999). From black to African American - a new social representation. Westport: Praeger.

Ribeiro, D. (1970). As Américas e a civilização. Rio de Janeiro: Civilização Brasileira.

Sherif, M. \& Sherif, C. (1969). Ingroup and intergroup relations. Em M. Sherif \& C.W. Sherif (Orgs.), Social psychology (pp. 221-266). New York: Harper \& Row.
Tajfel, H. (1969). The formation of national attitudes: a social psychological perspective. Em M. Sherif (Org.), Interdisciplinary relationships in the social sciences (pp. 137-176). Chicago: Aldine.

Tajfel, H., Flament, C., Billig, M. G. \& Bundy, R. F. (1971). Social categorization and intergroup behaviour. European Journal of Social Psychology, 1, 149-77.

Windisch, U. (1978). Xenophobie? - logique de la pensée populaire. Lausanne: L'Age d'Homme.

Recebido em 05.08.2003

Primeira decisão editorial em 19.10.2004

Versão final em 03.11.2004

Aceito em 14.11.2004 